\title{
Influence of Stream Location in a Drainage Network on the Index of Biotic Integrity
}

\author{
Lewis L. Osborne, Steven L. Kohler, And Peter B. Bayley \\ Center for Aquatic Ecology. Illinois State Natural History Survey \\ 607 East Peabody Drive. Champaign. Illinois 61820, USA \\ David M. Day and William A. Bertrand \\ Streams Program, Illinois Department of Conservation \\ Aledo, Illinois 61231. USA \\ Michael J. WiLeY \\ School of Natural Resources, University of Michigan \\ Ann Arbor, Michigan 48109. USA \\ RANDY SAUER \\ Streams Program. Illinois Department of Conservation \\ Carlyle. Illinois 62231. USA
}

\begin{abstract}
The index of biotic integrity (IBI) has become a widely used tool for assessing the condition of stream fish communities and the overall biological status of streams. Because the location of a stream in a drainage network can influence the species richness of fish communities and because species richness is an important component of the IBI, we examined the influence of stream spatial location on the IBI. We found that IBI scores for headwater streams in three Illinois drainage basins were significantly lower than those calculated for tributary streams of similar size connecting directly to larger streams. This difference in IBI was related to the increased species richness and to a greater number of sucker and darter species in tributaries that drain into larger. main-channel streams. Because of the influence of tributary location on the IBI, expected values for headwater tributary streams should be developed independently from those developed for main-channel tributary streams. Failure to do so can result in a substantial underestimation of the IBI of headwater tributary streams or an overestimation of main-channel tributaries.
\end{abstract}

The index of biotic integrity (IBI: Karr 1981) has been used widely for assessing environmental degradation of lotic ecosystems (Ohio Environmental Protection Agency 1988; Hite and Bertrand 1989; Fausch et al. 1990; Lyons, in press). The IBI is a composite index, comprising metrics (generally 12) that reflect structural and functional characteristics of fish communities (Karr et al. 1986). These metrics include trophic structure (proportions of omnivores, insectivorous cyprinids, and piscivores), species richness and abundances, taxonomic richness (numbers of darter, sunfish, sucker, and intolerant species, and sometimes the proportion of green sunfish), and disease frequency. Each metric is scored as a 1, a 3 , or a 5 depending upon whether it deviates strongly, deviates moderately, or approximates the anticipated condition for a quality stream of a similar size (generally assessed by stream order) in a given region. Because of the IBI's reported sensitivity to broad ecological conditions (Angermeier and Karr 1986; Karr et al. 1986; Fausch et al. 1990), its widespread application, and its proposed use as an index to set regulatory standards for stream quality (Fausch et al. 1990), it is important to consider factors that can influence the IBI and its expectations independently of environmental degradation.

The location of a stream in a drainage network can significantly affect the number of fish species in the community. Osborne and Wiley (1992) reported significantly fewer species of fish in loworder, tributary streams in the headwaters of a drainage network than in similar-size streams that drained into higher-order, main-channel streams in the lower half of the drainage networks. Such tributaries of main-channel streams have been referred to as adventitious streams (Gorman 1986). Observed differences in species richness appeared to be related to proximity to refugia associated with higher-order streams and differential rates of colonization following disturbances (Osborne and Wiley 1992). Because species richness is an important metric in the IBI and is related to other 

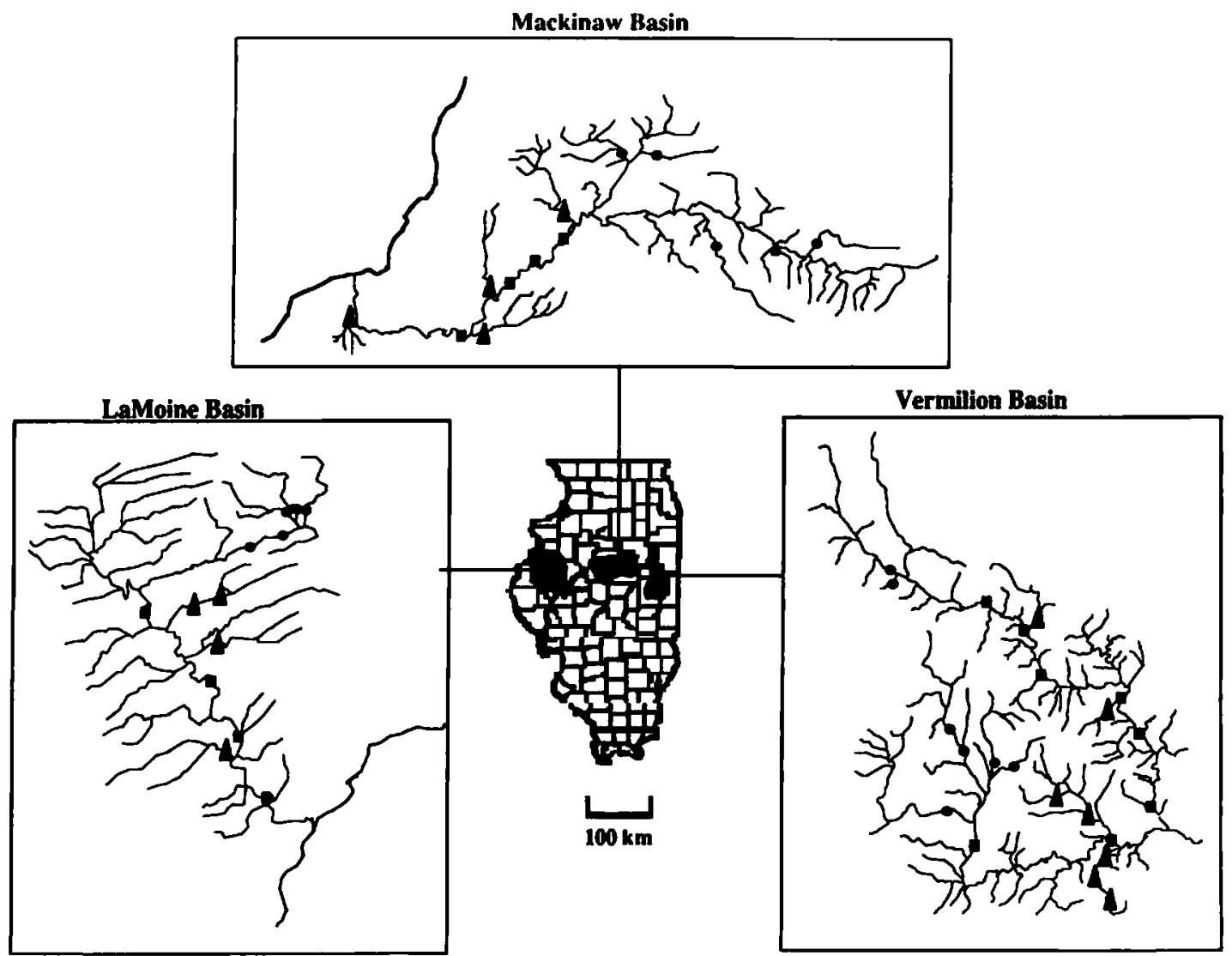

FIGURE 1.-Locations of headwater tributary (circles), main-channel tributary (triangles), and main-channel (squares) sampling stations in the LaMoine, Mackinaw, and Vermilion river basins in Illinois.

metrics, it is reasonable to assume that the location of a stream within a drainage network may also influence IBI scores within a region. Such a relationship would require that different expected values, or standards, be adopted for low-order streams that have different positions in the drainage network.

The purposes of this study were to determine if headwater tributary streams had significantly lower IBI scores than low-order, main-channel tributary streams in three midwestern drainage networks and to identify some of the components of the IBI that are influenced by the location of streams within a drainage network.

\section{Methods}

Fish were collected from 20 stations in the Vermilion River basin (drainage area, $2,312 \mathrm{~km}^{2}$ ) in east-central Illinois, 13 stations in the Mackinaw River basin $\left(3,011 \mathrm{~km}^{2}\right)$ in central Illinois, and 13 stations in the LaMoine River basin $\left(3,521 \mathrm{~km}^{2}\right)$ in west-central Illinois (Figure 1). Sampling stations were selected to represent a range of stream sizes, spatial locations within a drainage network, and environmental conditions. Row-crop agriculture (corn and soybeans) is the dominant activity in each basin and generally accounts for more than $90 \%$ of the land use (e.g., Osborne and Wiley 1988). Additional details on basin characteristics were reported by Day et al. $(1990,1992)$, Wiley et al. (1990), and Osborne and Wiley (1992).

Each sampling station was assigned to one of three station categories that reflected stream size and general spatial location (Osborne and Wiley 1992): headwater tributary (HT), main-channel tributary (MT), and main-channel (MC) streams (Table 1). Main-channel stations were on order-5 (sensu Strahler 1957) or higher streams with drainage areas greater than $259 \mathrm{~km}^{2}$. Tributaries with drainage areas less than $259 \mathrm{~km}^{2}$ were divided into MT and HT streams. Headwater tributary streams were low-order $(1-4)$ streams in the head- 
water portion (upper half) of a drainage network; they flowed into other HT streams or joined with other HT streams to form main channels (Figure 1). To determine upper and lower halves of a basin, a line perpendicular to the general direction of water flow in each basin was adjusted until an obvious main channel was detectable in the lower portion of the basin but not in the upper portion. Main-channel tributary streams were similar in size to HT streams but were in the lower portion of a drainage network and flowed directly into $\mathrm{MC}$ streams or into other MT streams that flowed into MC streams (Osborne and Wiley 1992). No significant differences were found in the size (stream order or drainage area) of HT and MT streams pooled across basins. The distance between MT stations and the nearest downstream MC stream ranged from 0.2 to $20 \mathrm{~km}$.

Fish collections from the Mackinaw River and the LaMoine River basins were made by the IIlinois Department of Conservation during the summers of 1987 and 1988, respectively. Fish collections in the Vermilion River basin were made by the Illinois Natural History Survey in October 1984 and 1985 . Tributary sampling stations were generally $100 \mathrm{~m}$ long and MC stations ranged from 100 to $300 \mathrm{~m}$. Because the streams had various widths and depths, fish were collected with one of two sampling techniques. All HT and MT stream reaches and $M C$ reaches with depths less than 1 $\mathrm{m}$ were sampled with a 9.1-m electric seine (Bayley et al. 1989) powered by a portable AC generator $(1,500 \mathrm{~W}, 120 \mathrm{~V})$. The gear was fished upstream through the reach, and at least three individuals (including the two seine operators) collected stunned fish with $6.35-\mathrm{mm}$-mesh dip nets. In MC reaches with mean depths greater than $1 \mathrm{~m}$, fish were collected with a two-person, threephase, triple-boom, boat-mounted electrofisher powered by an AC generator $(3,000 \mathrm{~W}, 230 \mathrm{~V})$. Small fish were preserved in $7 \%$ formalin and returned to the laboratory for identification and enumeration. Larger fish were identified, measured, and released.

On the basis of an earlier gear efficiency study (Bayley and Dowling 1990), we assume that fish communities at MC stations sampled with either electric seine or boat-mounted gear were less efficiently sampled than were HT and MT stations that were sampled with the electric seine. Estimates of fish species richness at MC stations should therefore be viewed as more conservative than estimates from tributary stations. For this reason we have chosen to minimize comparisons of MC
TABLE 1.-Calculated indexes of biotic integrity (IBI), stream order, and number of fish species $(N)$ collected at each sampling station, categorized according to drainage network location and river basin.

\begin{tabular}{|c|c|c|c|c|c|c|c|c|}
\hline \multicolumn{3}{|c|}{$\begin{array}{l}\text { Headwater } \\
\text { tributaries }\end{array}$} & \multicolumn{3}{|c|}{$\begin{array}{l}\text { Main-channel } \\
\text { tributaries }\end{array}$} & \multicolumn{3}{|c|}{ Main channels } \\
\hline IBI & Order & $(M)$ & IBI & Order & $(N)$ & IBI & Order & $(N)$ \\
\hline \multicolumn{9}{|c|}{ LaMoine River basin } \\
\hline 27 & 4 & 9 & 45 & 3 & 23 & 44 & 5 & 20 \\
\hline 38 & 3 & 11 & 43 & 3 & 17 & 52 & 5 & 20 \\
\hline 38 & 2 & 13 & 34 & 3 & 12 & 45 & 5 & 12 \\
\hline 37 & 4 & 12 & 38 & 3 & 13 & 47 & 5 & 21 \\
\hline 38 & 2 & 17 & & & & & & \\
\hline \multicolumn{9}{|c|}{ Mackinaw River basin } \\
\hline 58 & 3 & 22 & 47 & 4 & 24 & 47 & 6 & 32 \\
\hline 34 & 4 & 10 & 45 & 4 & 26 & 47 & 6 & 28 \\
\hline 34 & 4 & 16 & 53 & 4 & 36 & 56 & 6 & 31 \\
\hline 49 & 4 & 22 & 49 & 2 & 24 & 50 & 6 & 28 \\
\hline 49 & 3 & 21 & & & & & & \\
\hline \multicolumn{9}{|c|}{ Vermilion River basin } \\
\hline 30 & 4 & 12 & 50 & 4 & 28 & 50 & 5 & 33 \\
\hline 40 & 4 & 19 & 46 & 4 & 16 & 44 & 5 & 23 \\
\hline 36 & 3 & 15 & 54 & 2 & 17 & 48 & 5 & 23 \\
\hline 52 & 3 & 22 & 56 & 2 & 21 & 50 & 5 & 26 \\
\hline 41 & 1 & 14 & 52 & 2 & 23 & 52 & 5 & 18 \\
\hline 40 & 2 & 9 & 52 & 3 & 23 & 54 & 6 & 31 \\
\hline 36 & 4 & 15 & 42 & 2 & 17 & & & \\
\hline
\end{tabular}

data with HT and MT data, and to concentrate on comparisons of $\mathrm{HT}$ with MT data. Despite the use of the same gear at HT and MT stations, sampling efficiency undoubtedly varied among stations. However, because (1) there were no significant differences in the sizes of HT and MT streams, (2) a similar sampling effort was made at each HT and MT station, and (3) similar environmental and land use conditions existed across the range in size of tributary stations sampled, we assume that sampling did not vary systematically between HT and MT stations.

Data on fish composition and abundance were used to calculate an IBI for each station according to procedures described by Hite and Bertrand (1989). Metric scores were corrected for stream size and IBI region (Karr et al. 1986) with information developed specifically for Illinois (Hite and Bertrand 1989). Because of incomplete information on disease, the average of the other 11 metrics was substituted for the disease metric score (Hite and Bertrand 1989).

All statistical analyses were performed with SYSTAT (Wilkinson 1988) with a significance level of $P=0.05$. Dependent variables were appropriately transformed to meet the statistical assumptions of the parametric tests. The effects of drainage basin (Mackinaw, Vermilion, and LaMoine) 
TABLE 2.-Results of two-way analysis of variance of the index of biotic integrity (IBI), of transformed (loge[p]) proportions of omnivores, piscivores, and insectivorous cyprinids, of transformed $\left(\log _{e}[n+1]\right)$ numbers of sunfish, sucker, and darter species, of species richness, and of total numbers of individuals at stations in the LaMoine (Lam), Mackinaw (Mac), and Vermilion (Ver) river basins with respect to station location (headwater tributary, HT; mainchannel tributary, MT) and drainage basin. Numbers are the $F$-values for each source of variation; values in parentheses are percentages of the explained variance. Asterisks denote significance at $P<0.05^{*}, P<0.01^{* *}$, or $P<0.001 * * *$.

\begin{tabular}{|c|c|c|c|c|}
\hline \multirow[b]{2}{*}{ Variable } & \multicolumn{3}{|c|}{ Source of variation } & \multirow[b]{2}{*}{ Posthoc contrasts $(P<0.05)$} \\
\hline & Location & Basin & Basin $\times$ location & \\
\hline IBI & $\begin{array}{l}7.29 * \\
(50 \%)\end{array}$ & $\begin{array}{l}4.94^{*} \\
(34 \%)\end{array}$ & $\begin{array}{l}1.24 \\
(7 \%)\end{array}$ & $\begin{array}{l}\mathrm{MT}>\mathrm{HT} \\
(\mathrm{Mac}=\mathrm{Ver})>\mathrm{Lam}\end{array}$ \\
\hline$\%$ omnivores & $\begin{array}{c}0.20 \\
(2 \%)\end{array}$ & $\begin{array}{l}6.64^{* *} \\
(77 \%)\end{array}$ & $\begin{array}{l}0.75 \\
(9 \%)\end{array}$ & Ver $>$ Lam $>$ Mac \\
\hline $\begin{array}{l}\% \text { insectivorous } \\
\text { cyprinids }\end{array}$ & $\begin{array}{l}0.03 \\
(1 \%)\end{array}$ & $\begin{array}{c}4.53^{*} \\
(70 \%)\end{array}$ & $\begin{array}{r}9.95 \\
(15 \%)\end{array}$ & Mac $>($ Verm $=$ Lam $)$ \\
\hline$\%$ piscivores & $\begin{array}{l}0.02 \\
(1 \%)\end{array}$ & $\begin{array}{r}0.52 \\
(31 \%)\end{array}$ & $\begin{array}{l}0.15 \\
(9 \%)\end{array}$ & \\
\hline $\begin{array}{l}\text { Number of } \\
\text { darters }\end{array}$ & $\begin{array}{l}10.16^{* * *} \\
(35 \%)\end{array}$ & $\begin{array}{l}5.04^{*} \\
(17 \%)\end{array}$ & $\begin{array}{l}13.13^{* * *} \\
(45 \%)\end{array}$ & $\begin{array}{l}\text { Ver: } M T>H T \\
\text { Mac: } M T=H T \\
\text { Lam: } M T>H T\end{array}$ \\
\hline $\begin{array}{l}\text { Number of } \\
\text { sunfishes }\end{array}$ & $\begin{array}{r}1.67 \\
(23 \%)\end{array}$ & $\begin{array}{r}2.51 \\
(34 \%)\end{array}$ & $\begin{array}{r}2.20 \\
(30 \%)\end{array}$ & \\
\hline $\begin{array}{l}\text { Number of } \\
\text { suckers }\end{array}$ & $\begin{array}{l}18.13^{\text {*n*t }} \\
(86 \%)\end{array}$ & $\begin{array}{r}1.61 \\
(8 \%)\end{array}$ & $\begin{array}{c}0.39 \\
(2 \%)\end{array}$ & $\mathrm{MT}>\mathrm{HT}$ \\
\hline $\begin{array}{l}\text { Species } \\
\text { richness }\end{array}$ & $\begin{array}{l}18.11^{* * * *} \\
(70 \%)\end{array}$ & $\begin{array}{l}6.55^{* * *} \\
(25 \%)\end{array}$ & $\begin{array}{l}0.53 \\
(2 \%)\end{array}$ & $\begin{array}{l}\mathrm{MT}>\mathrm{HT} \\
\mathrm{Mac}>\mathrm{Ver}>\mathrm{Lam}\end{array}$ \\
\hline $\begin{array}{l}\text { Number of } \\
\text { individuals }\end{array}$ & $\begin{array}{c}0.01 \\
(<1 \%)\end{array}$ & $\begin{array}{r}2.23 \\
(17 \%)\end{array}$ & $\begin{array}{l}1.15 \\
(9 \%)\end{array}$ & \\
\hline
\end{tabular}

and network location (HT and MT) on the IBI, on the transformed $\left(\log _{e}[p]\right)$ proportion of omnivores, insectivorous cyprinids, and piscivores, and on the transformed $\left(\log _{e}[n+1]\right)$ number of sucker, darter, and sunfish species at each station were examined by two-way analysis of variance. The Bonferroni procedure was applied to unplanned posthoc multiple comparisons to maintain the overall experiment-wide error rate at $P=$ 0.05 . We tested the hypothesis that there was no difference in the frequency of occurrence of the maximum IBI values among $H T$ and $M T$ stations (pooled for the three basins) with a binomial test (Siegel 1956).

A Jaccard community similarity coefficient (Digby and Kempton 1987) was calculated with species presence-absence data for each MT station and its closest downstream MC station to determine if the similarity in community structure decreased with increasing distance of the MT stations from the main channel. Similarity coefficients, which can range from 0.0 (no species in common) to 1.0 (all species shared), were related to the distance of the MT station to the main channel by simple linear regression.

\section{Results and Discussion}

We found significant effects of drainage basin and station location on IBI scores (Tables 1,2) but no significant basin $\times$ location interaction. Half the variation in IBI scores was explained by station location and $34 \%$ by drainage basin (Table 2). Unplanned multiple comparisons further indicated that the average IBI score for tributary (MT and HT) stations in the LaMoine River basin $(37.6 \pm 1.6$, mean $\pm \mathrm{SE})$ was significantly lower $(P<0.05)$ than the means for tributary stations in the Mackinaw (46.4 \pm 2.6$)$ and Vermilion (44.8 \pm 2.1 ) basins (Table 2).

The three basins occur in different IBI regions and have different expectation criteria (Hite and Bertrand 1989). They all are dominated by rowcrop agriculture; urban development constitutes less than $5 \%$ by area. The major land use difference among the basins is that the LaMoine has more agricultural feedlots (Day et al. 1992). Nutrient-rich runoff from feedlots might have contributed to the lower IBI values in the LaMoine basin. However, the LaMoine River samples were collected during the 1988 drought, whereas sam- 
ples from the other basins were taken in years of more normal precipitation, so it is likely that the lower IBI scores in the LaMoine basin simply reflect responses of the fish communities to natural year-to-year variation in weather conditions. Previous studies on midwestern warmwater streams have demonstrated the adverse effect of drought on fish communities (Larimore 1959; Giller and Twomey 1989; Bayley and Osborne, unpublished data), including decreases in fish species richness. Significantly fewer species of fish were found at tributary sampling stations in the LaMoine River basin (15 species) than were collected at tributary stations in the Vermilion (18 species) and Mackinaw (22 species) basins (Table 2). As did Kart et al. (1987) and Angermeier and Karr (1986), we found significant correlations $(P<0.01)$ between IBI scores and the number of fish species in each of the three basins (Mackinaw: $r=0.67, N=13$; Vermilion: $r=0.71, N=20$ : LaMoine: $r=0.83$, $N=13$ ). We also found significant interbasin variability in trophic (proportion of omnivores) and taxonomic (numbers of darters and suckers) structure among basins (Table 2). Whatever the cause for the lower IBI values, the significantly higher IBI scores at MT stations $(47.0 \pm 1.6)$ compared with HT stations ( $39.9 \pm 1.9$; Table 2$)$ is evidence that spatial location of tributary streams in a drainage network can influence the IBI across a range of drainage basins, years, and environmental conditions.

Several factors may have accounted for the significantly higher IBI scores at MT stations compared with HT stations. Habitat diversity greatly influences biotic integrity (Karr et al. 1986; Angermeier and Schlosser 1987). We attempted to minimize this effect by selecting tributary stations as similar to one another as possible. Osborne and Wiley (1992) were unable to identify differences in several physical habitat variables (stream size, discharge variability, habitat diversity, channel gradient) at the MT and HT sampling stations in the Vermilion and Mackinaw basins. Nonetheless, other habitat variables not considered might account for the observed differences in IBI scores between HT and MT streams. For this reason we cannot reject the possibility that differences in the habitat quality at HT and MT streams may explain some of the differences observed.

As previously mentioned, species richness is an important metric in the IBI (Karr et al. 1986). We found significantly more $(P<0.0001)$ species of fish at MT stations $(21.9 \pm 1.5)$ than at HT stations (15.2 \pm 1.1 ; Table 2$)$. Higher species rich- ness in MT than in HT streams may have resulted from greater immigration and recolonization rates associated with the closer proximity of MT stations to main channels (Osborne and Wiley 1992). It was hypothesized (Horwitz 1978; Grossman et al. 1982) that larger streams provide species inhabiting nearby tributary streams with refugia during periods of disturbance (e.g., droughts) and thus serve as a subsequent species pool for recolonization.

Jaccard community similarity coefficients for MT stations and the closest MC station ranged from 0.14 to 0.58 . Despite this broad range we were unable to detect a significant relationship between the distance of MT stations from main channels and the similarity coefficients $(F=1.27$; df $=1,14 ; P=0.28 ; r^{2}=0.09$ ); however, the slope was negative as expected. A larger range of distances, or an increased number of samples in future analyses should clarify this relationship. Our results do suggest that species richness and IBI scores at MT stations within $20 \mathrm{~km}$ of the main channel are similar.

The influence of stream location within a drainage network on species richness and IBI scores has important implications for the development of IBI "expectation criteria" (Karr et al. 1986). Fausch et al. (1984) suggested that any application of the IBI to assess human impacts must control for stream size and zoogeography. To account for zoogeographic influences, IBI expectation criteria are developed regionally. To account for the influence of stream size on species richness, stream order or drainage area is plotted against species richness to generate lines of expected number of species for streams within a region. Because the location of stream channels within a drainage network appears to influence IBI scores, resource managers may underestimate the biotic integrity of HT streams or overestimate the quality of MT streams, depending on which data are used to establish the expectation criteria.

In central Illinois, an IBI of 45 was recommended as the minimum score for a stream rated as "good" (Karr et al. 1986). Fifteen of our tributary stations had IBI scores of $\mathbf{4 5}$ or greater (Figure 2), of which only four were HT streams (Table 1). The probability of four of 15 stations belonging to the HT station category was significantly nonrandom $(P=0.05)$ according to a binomial test. These results suggest that $\mathrm{MT}$ stations constituted a disproportionate number of the stream reaches categorized as "good" within the three basins. Conversely, of 17 tributary stations with IBI scores 


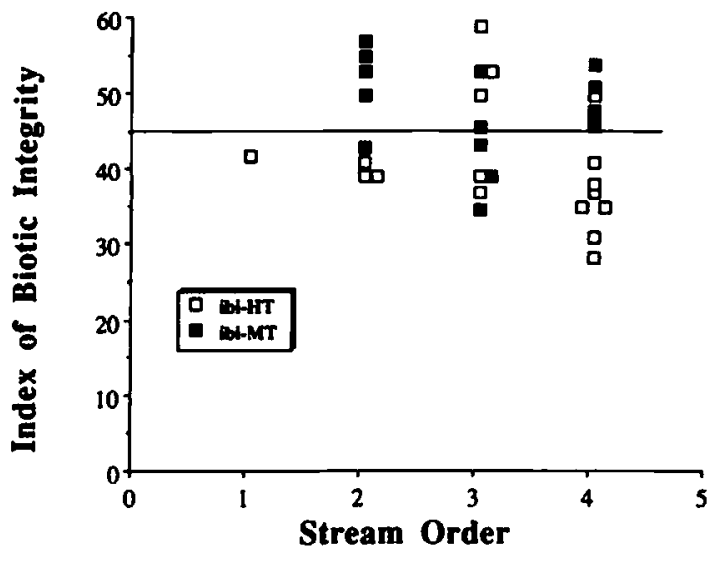

FIGURE 2.-Index of biotic integrity (IBI) scores for headwater tributary (HT) and main-channel tributary (MT) stations in the LaMoine, Mackinaw, and Vermilion river basins versus stream order. The horizontal line marks $\mathrm{IBI}=45$, the recommended minimum score to achieve a rating of "good" in Illinois.

less than 45 (Figure 2), only 4 were MT stations (Table 1). The probability that four of 17 stations would be MT stations was also significantly nonrandom $(P=0.025)$, suggesting that $H T$ reaches constituted a disproportionate number of the apparently poor quality stream reaches.

To illustrate the potential influence of tributary location on the IBI, we combined the data from the three Illinois basins and developed expectation relations for species richness (Figure 3) according to the procedures in Karr et al. (1986). These relationships were used to generate a table of the minimum number of species required to achieve an IBI component rating of 5 for each stream order (Table 3). Based on the "expectation lines" in Figure 3A, 6 of 17 HT stations (35\%) and 11 of 15 MT stations (73\%) would have received scores of 5 (Tables 1,3 ). If the species-rich MT stations were excluded from the analysis (Figure $3 \mathrm{C}$ ), three additional HT stations ( 9 of 17 , or $53 \%$ ) would receive a score of 5 . Exclusion of $\mathrm{HT}$ stations from the analysis (Figure 3B) would not change the number of $\mathrm{MT}$ stations receiving a score of 5 in our study, but it could in other studies because it raises the minimum species richness required for third- and fourth-order streams to receive a score of 5 (Table 3 ). The results from these three Illinois basins suggest that the present practice of pooling all streams to derive the standard (i.e., of not accounting for the location of tributary streams within a drainage network) can result in an underestimation of the biotic integrity of headwater tributary streams and an overestimation of MT stream integrity.

We also examined the infiuence of tributary location and drainage basin affiliation on other metrics of the IBI (Table 2). Although differences in trophic structure occurred that could be attributed to drainage basin (Table 2), tributary location in a drainage network did not significantly influence the trophic composition of the fish communities in small streams, as indicated by the proportions of omnivores, insectivorous cyprinids, and piscivores (Table 2).

As with the trophic results, no significant influence of tributary location on the total number of individuals or the number of sunfish species at sampling stations was detected (Table 2). However, significantly more sucker species $(P<0.001)$ were found at MT stations than at HT stations, and tributary location accounted for $86 \%$ of the variation in the number of sucker species caught (Table 2). The average number of sucker species was similar at MT stations (4.1) and MC sites (6.7), but much lower at HT stations (1.5). This pattern reflects the restriction of these species to the lower basins, except for short-term reproductive migrations that are relatively limited in HT streams. The influence of tributary location on the number of suckers further illustrates the potential influence of this landscape attribute on the IBI.

Significant effects of tributary location $(P<0.01)$ on the number of darter species at stations was also found, but only in two of the three basins (Table 2). The inconsistency in the pattern of darter abundance does not provide adequate evidence to support or reject the hypothesis of the importance of spatial location on this IBI metric. Preliminary analyses by Bayley and Dowling (1990) indicate that the catchability of darters diminishes when the quality of their habitat improves, so future analyses that correct for sampling efficiency should clarify this relationship.

Our results suggest that at least 3 of the 12 IBI metrics, species richness and the numbers of darter and sucker species, are influenced by the location of a tributary within a drainage network. Further, these findings indicate that prior to constructing species-stream order expectation graphs, resource managers should first ascertain whether the location of tributary streams within a drainage network influences the number of fish species. If such spatial variation is found, at least two expectation relationships should be developed. One should include low-order, headwater tributary streams and the other should include low-order, 

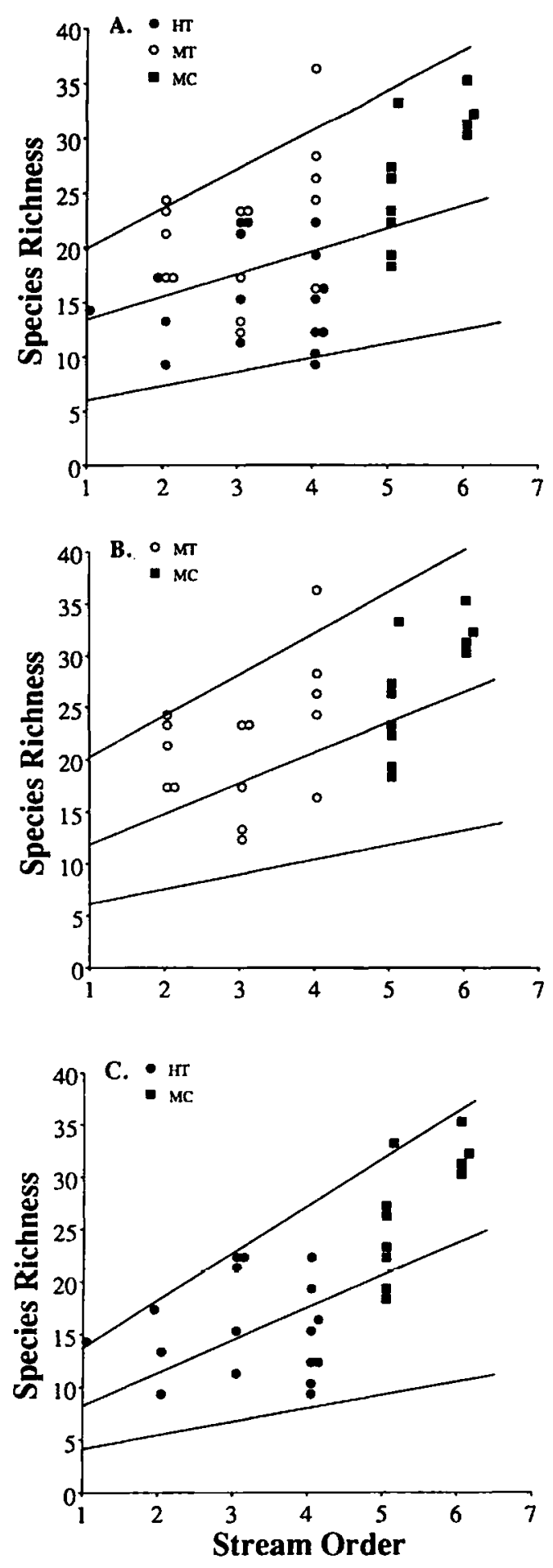

FIGURE 3.-Species richness expectation graphs for calculating indexes of biotic integrity (IBI) with data from (A) all station categories (main-channel tributary, MT; headwater tributary, HT; and main channel, MC), (B)
TABLE 3.-Minimum species richness required to fall within the upper one-third of the expectation criteria curve, or "good" range, with respect to stream order when all stations or combinations of main-channel tributary (MT), main-channel (MC), and headwater tributary (HT) stations are used. These data were interpreted from graphs in Figure 3.

\begin{tabular}{lcccc}
\hline \multirow{2}{*}{$\begin{array}{c}\text { Station } \\
\text { categories } \\
\text { included }\end{array}$} & \multicolumn{5}{c}{ Stream order } \\
\cline { 2 - 5 } & 1 & 2 & 3 & 4 \\
\hline All & 13 & 16 & 18 & 20 \\
MT and MC & 13 & 16 & 19 & 23 \\
HT and MC & 8 & 11 & 14 & 17 \\
\hline
\end{tabular}

main-channel tributary streams, as in Figure 3. Failure to account for locational influences of streams is likely to result in an erroneous assessment of the biotic integrity of tributary streams within a region.

In conclusion, we recommend that managers evaluate species richness and community structure metrics for influences of tributary location in a drainage network. If such spatial influences are detected, they should be incorporated into the development of regional expectation criteria. The procedures used in this paper can serve as a guide for assessing the importance of tributary location and for modifying IBI expectation criteria. Although our criteria for distinguishing between HT and MT streams were adequate to discern distinct patterns in species richness (Osborne and Wiley 1992) and IBI scores across the three basins, they may need to be modified for use in other basins or regions. Future research in the area of spatial statistics, land use ecology, stream network analysis, and gear efficiency will facilitate the development of guidelines to better distinguish between headwater and main-channel tributary streams and to assess the geographic extent of this drainage network pattern. Developers of the IBI recognized the importance of incorporating professional judgement into the scoring metrics, thereby allowing for the continued evolution of the index as a management tool.

only MT and MC stations, and (C) only HT and MC stations. Data are from the LaMoine, Mackinaw, and Vermilion river basins. The upper line in each graph represents maximum species richness per stream order, fit by eye. Trisection of the area below each maximumrichness line creates regions in which richness would receive scores of (from top to bottom) 5,3 , and 1 as an IBI metric. 


\section{Acknowledgments}

This research was supported by grants from Federal Aid in Sport Fish Restoration projects F-43-R and F-63-R (administered by the U.S. Fish and Wildlife Service and the Illinois Department of Conservation), the Illinois Department of Natural Resources, and the Illinois Natural History Survey. Earlier versions of this manuscript were greatly improved by the comments of $\mathbf{R}$. W. Larimore, R. Newman, and D. Blodgett. Participation in the Streams Discussion Group of the Illinois Natural History Survey's Center for Aquatic Ecology greatly helped the development of concepts within this manuscript. Numerous individuals were responsible for the collection of the Vermilion River data, including T. Kwak, G. Warren, S. Sobaski, D. Dowling, T. Skelley, C. Mayer, B. Fields, and an army of interns.

\section{References}

Angermeier, P. L., and J. R. Karr. 1986. Applying an index of biotic integrity based on stream-fish communities: considerations in sampling and interpretation. North American Journal of Fisheries Management 6:418-429.

Angermeier, P. L., and I. J. Schlosser. 1987. Assessing biotic integrity in the fish community of a small Illinois stream. North American Journal of Fisheries Management 7:331-338.

Bayley, P. B., and D. C. Dowling. 1990. Gear efficiency calibration for stream and river sampling. Illinois Natural History Survey, Center for Aquatic Ecolo8y, Technical Report 90/8, Champaign.

Bayley, P. B., R. W. Larimore, and D. C. Dowling. 1989. Electric seine as a fish-sampling gear in streams. Transactions of the American Fisheries Society 118: 447-453.

Day, D., R. Sauer, and W. Bertrand. 1990. An evaluation of the fisheries of the Mackinaw River basin in central Illinois. Proceedings of the Illinois Academy of Science 83:82-100.

Day, D. M., R. W. Sauer, L. McGuire, W. A. Bertrand, and L. A. Jahn. 1992. An assessment of fishes in the LaMoine River basin in west-central Illinois. Proceedings of the Illinois Academy of Science 85: 47-72.

Digby, P. G. N., and R. A. Kempton. 1987. Multivariate analysis of ecological communities. Population and community biology series. Chapman and Hall. New York.

Fausch, K. D., J. R. Karr, and P. R. Yant. 1984. Regional application of an index of biotic integrity based on stream fish communities. Transactions of the American Fisheries Society 113:39-55.

Fausch, K. D., J. Lyons, J. R. Kart, and P. L. Angermeier. 1990. Fish communities as indicators of environmental degradation. American Fisheries Society Symposium 8:123-144.
Giller, P., and H. Twomey. 1989. Benthic invertebrates and fish diets; a natural experiment following a major disturbance event. Bulletin of the British Ecological Society 20(3):205-209.

Gorman, O. T. 1986. Assemblage organization of stream fishes: the effects of rivers on adventitious streams. American Naturalist 128:611-616.

Grossman. G. D.. P. B. Moyle, and J. O. Whitaker. 1982. Stochasticity in structural and functional characteristics of an Indiana stream fish assemblage: a test of community theory. American Naturalist 120:423-454.

Hite, R. L., and W. A. Bertrand. 1989. Biological stream characterization (BSC): a biological assessment of Illinois stream quality. Illinois State Water Plan Task Force Special Report 13 to the Illinois Environmental Protection Agency, Report IEPA-WPC-89. 275. Springfield.

Horwitz, R. J. 1978. Temporal variability patterns and the distributional patterns of stream fishes. Ecological Monographs 48:307-321.

Karr, J. R. 1981. Assessment of biotic integrity using fish communities. Fisheries (Bethesda) 6(6):21-27.

Karr, J. R., K. D. Fausch, P. L. Angermeier, P. R. Yant, and I. J. Schlosser. 1986. Assessing biological integrity in running waters: a method and its rationale. Illinois Natural History Survey Special Publication 5:1-28.

Karr, J. R., P. R. Yant, K. D. Fausch, and I. J. Schlosser. 1987. Spatial and temporal variability of the index of biotic integrity in three midwestern streams. Transactions of the American Fisheries Society 116: $1-11$.

Larimore, R. W., W. F. Childers, and C. Heckrotte. 1959. Destruction and re-establishment of stream fish and invertebrates affected by drought. Transactions of the American Fisheries Society 88:261285.

Lyons, J. In press. Using the index of biotic integrity (IBI) to measure environmental quality in warmwater streams of Wisconsin. Wisconsin Department of Natural Resources, Technical Research Report. Monona.

Ohio Environmental Protection Agency. 1988. Biological criteria for the protection of aquatic life. Volume II: users manual for biological field assessment of Ohio surface waters. Ohio Environmental Protection Agency, Columbus.

Osborne, L. L., and M. J. Wiley. 1988. Empirical relationships between land use/cover and stream water quality in an agricultural watershed. Journal of Environmental Management 26:9-27.

Osborne. L. L., and M. J. Wiley. 1992. Influence of tributary spatial position on the structure of warmwater fish communities. Canadian Journal of Fisheries and Aquatic Sciences 49:671-681.

Siegel, S. 1956. Nonparametric statistics for the behavioral sciences. McGraw-Hill, New York.

Strahler, A. N. 1957. Quantitative analysis of watershed geomorphology. Transactions of the American Geophysical Union 38:913-920. 
Wiley, M. J., L. L. Osborne, and R. W. Larimore. 1990. Longitudinal structure of an agricultural prairie river system and its relationship to current stream ecosystem theory. Canadian Journal of Fisheries and Aquatic Sciences 47:373-384.
Wilkinson, L. 1988. Systat: the system for statistics. Systat, Evanston, Illinois.

Received June 7, 1991 Accepted February 26, 1992 